\title{
Occupational Health Hazards among Healthcare Workers in Kampala, Uganda
}

\author{
Rawlance Ndejjo, ${ }^{1}$ Geofrey Musinguzi, ${ }^{1}$ Xiaozhong Yu, ${ }^{2}$ Esther Buregyeya, \\ David Musoke, ${ }^{1}$ Jia-Sheng Wang, ${ }^{2}$ Abdullah Ali Halage, ${ }^{1}$ Christopher Whalen, ${ }^{3}$ \\ William Bazeyo, ${ }^{1}$ Phillip Williams, ${ }^{2}$ and John Ssempebwa ${ }^{1}$ \\ ${ }^{1}$ Department of Disease Control and Environmental Health, School of Public Health, College of Health Sciences, \\ Makerere University, P.O. Box 7072, Kampala, Uganda \\ ${ }^{2}$ Department of Environmental Health Sciences, College of Public Health, University of Georgia, Athens, GA 30602, USA \\ ${ }^{3}$ Department of Epidemiology and Biostatistics, College of Public Health, University of Georgia, Athens, GA 30602, USA \\ Correspondence should be addressed to Geofrey Musinguzi; mgeof@musph.ac.ug
}

Received 8 September 2014; Revised 6 January 2015; Accepted 6 January 2015

Academic Editor: Habibul Ahsan

Copyright (C) 2015 Rawlance Ndejjo et al. This is an open access article distributed under the Creative Commons Attribution License, which permits unrestricted use, distribution, and reproduction in any medium, provided the original work is properly cited.

Objective. To assess the occupational health hazards faced by healthcare workers and the mitigation measures. Methods. We conducted a cross-sectional study utilizing quantitative data collection methods among 200 respondents who worked in 8 major health facilities in Kampala. Results. Overall, $50.0 \%$ of respondents reported experiencing an occupational health hazard. Among these, $39.5 \%$ experienced biological hazards while $31.5 \%$ experienced nonbiological hazards. Predictors for experiencing hazards included not wearing the necessary personal protective equipment (PPE), working overtime, job related pressures, and working in multiple health facilities. Control measures to mitigate hazards were availing separate areas and containers to store medical waste and provision of safety tools and equipment. Conclusion. Healthcare workers in this setting experience several hazards in their workplaces. Associated factors include not wearing all necessary protective equipment, working overtime, experiencing work related pressures, and working in multiple facilities. Interventions should be instituted to mitigate the hazards. Specifically PPE supply gaps, job related pressures, and complacence in adhering to mitigation measures should be addressed.

\section{Background}

Worldwide, the healthcare workforce represents $12 \%$ of the working population [1]. Healthcare workers operate in an environment that is considered to be one of the most hazardous occupational settings [2-4]. In addition to the usual workplace related exposures, healthcare workers encounter diverse hazards due to their work related activities [5, 6]. In spite of this knowledge, the healthcare work environment continues to be neglected by governments and organizations [7]. A higher annual prevalence of back pain (77\%) among healthcare workers compared to other occupational groups has been reported [8-11]. Back injuries are associated with a direct cost of $\$ 37,000$ and an indirect cost ranging from $\$ 147,000$ to $\$ 300,000$ [8]. In fact, ergonomic related injuries pose a significant health risk to workers and yet it is the most prevalent occupational injury in healthcare industry [12]. Healthcare workers are exposed to blood-borne infections which usually expose them to diseases such as HIV, TB, and hepatitis B and hepatitis C [1]. Substantial morbidity and mortality among these workers inevitably lead to loss of skilled personnel and adversely impact healthcare services which are already strained in many low and middle income countries.

In sub-Saharan Africa, the scarcity of human resource for health is described as a humanitarian resource crisis due to significant emigration of trained professionals, difficult working conditions, poor salaries, low motivation, and high burden of infectious diseases, particularly HIV/AIDS [1315]. Evidence from sub-Saharan Africa indicates that healthcare workers are frequently exposed to chemical, biological, physical, and psychosocial occupational hazards $[6,16]$. They 
are constantly in contact with patients that expose them to infections and thus require proper protective measures to reduce their risk of acquisition of disease or injury. Data on occupational hazards among healthcare workers and their mitigation measures remain scarce in most of subSaharan Africa and Uganda in particular. Understanding the predisposing factors for occupational hazards among healthcare workers is needed to inform occupational health and safety policy and programs for healthcare workers. This study assessed the occupational hazards and their control measures in eight major hospitals in Kampala, Uganda.

\section{Methods}

2.1. Study Design and Setting. The study was cross-sectional in design and involved quantitative data collection methods. It was carried out in Kampala district, Uganda's capital city. There are over 873 health facilities in Kampala of which 26 are government owned, 22 private not for profit, and 825 private for profit [17].

2.2. Sampling. Eight (8) major hospitals were included in this study. These were purposively selected based on size and patient capacity. The selection ensured a combination of governmental, private for profit, and private not for profit facilities. These included Mulago Hospital and Butabika hospital, which are public facilities; Mengo hospital, Kibuli Muslim hospital, and Nsambya hospital, which are private not for profit; Kadic hospital, International Hospital Kampala, and Case Medical Centre which are private for profit facilities. To select the respondents, sampling proportionate to size was used to determine the number of healthcare workers to be interviewed from each hospital. At the hospital, all healthcare workers who were present at the facility were considered for the study. In cases where the number of workers present was higher than the required number of respondents, simple random sampling was used to select those to be interviewed.

2.3. Studied Population. The study population comprised a range of healthcare workers working in selected health facilities. These included doctors, nurses, clinical officers, and midwives. Table 1 shows the general characteristics of the studied healthcare workers. Of the 200 participants, the majority were females $(71.5 \%)$, were of age over 30 years (55.0\%), were married (53.5\%), were Christians (86.5\%), and earned over 500,000 Uganda shillings (approx. US \$200) per month (52.5\%). Just over half were nurses (50.5\%), $41 \%$ worked in private health facilities and $53.0 \%$ had practiced for five or more years. Most of them (70.5\%) worked beyond their normal working time, $28.0 \%$ worked in more than one facility, 38\% consumed alcohol, and $75.0 \%$ had less than 8 hours of sleep daily. Fifty nine (59) percent did not exercise frequently and most of them $(83.5 \%)$ reported to have experienced job related pressures. None smoked tobacco.

2.4. Data Collection. A standardized structured questionnaire adapted from the National Institute of Occupational
TABLE 1: Characteristics of studied health workers in major hospitals in Kampala, Uganda.

\begin{tabular}{|c|c|c|}
\hline Characteristic & Category & Total N (\%) \\
\hline Overall & & $200(100.0)$ \\
\hline \multirow{2}{*}{ Sex } & Male & $57(28.5)$ \\
\hline & Female & $143(71.5)$ \\
\hline \multirow{2}{*}{ Age } & $\leq 30$ years & $90(45.0)$ \\
\hline & $>30$ years & $110(55.0)$ \\
\hline \multirow{2}{*}{ Marital status } & Married & $107(53.5)$ \\
\hline & Single & $93(46.5)$ \\
\hline \multirow{2}{*}{ Religion } & Christians & $173(86.5)$ \\
\hline & Muslims & $27(13.5)$ \\
\hline \multirow{2}{*}{ Head of household } & No & $97(48.5)$ \\
\hline & Yes & $103(51.5)$ \\
\hline \multirow{2}{*}{ Cadre of health worker } & Nurses & $101(50.5)$ \\
\hline & Others & $99(49.5)$ \\
\hline \multirow{2}{*}{ Monthly income } & $\leq 500,000$ & $95(47.5)$ \\
\hline & $>500,000$ & $105(52.5)$ \\
\hline \multirow{3}{*}{ Type of health care facility } & Faith based & $48(24.0)$ \\
\hline & Government & $70(35.0)$ \\
\hline & Private & $82(41.0)$ \\
\hline \multirow{2}{*}{ Duration in service } & $<5$ years & $94(47.0)$ \\
\hline & $\geq 5$ years & $106(53.0)$ \\
\hline \multirow{2}{*}{ Wearing all necessary PPE } & Yes & $115(57.5)$ \\
\hline & No & $85(42.5)$ \\
\hline \multirow{2}{*}{ Working overtime } & No & $59(29.5)$ \\
\hline & Yes & $141(70.5)$ \\
\hline \multirow{2}{*}{ Working in multiple facilities } & No & $144(72.0)$ \\
\hline & Yes & $56(28.0)$ \\
\hline \multirow{2}{*}{ Alcohol consumption } & No & $162(81.0)$ \\
\hline & Yes & $38(19.0)$ \\
\hline \multirow{2}{*}{ Has frequent exercise } & No & $118(59.0)$ \\
\hline & Yes & $82(41.0)$ \\
\hline \multirow{2}{*}{ Daily hours of sleep } & $<8$ hours & $150(75.0)$ \\
\hline & $\geq 8$ hours & $50(25.0)$ \\
\hline \multirow{2}{*}{ Pressure from job } & No & $33(16.5)$ \\
\hline & Yes & $167(83.5)$ \\
\hline \multirow{2}{*}{ Tobacco smoking } & No & $200(100)$ \\
\hline & Yes & $0(0)$ \\
\hline
\end{tabular}

Safety and Health, US Center for Disease Control and Prevention, with modification to suit the local context consisting of both closed and open ended questions was used to collect the data.

The questionnaire collected data on the sociodemographic characteristics of the respondents including age, marital status, education level, and their work history. In addition, data was collected on the occupational health and safety practices of the healthcare workers, the hazards that they experienced in their work places, and the control measures in place to mitigate those hazards. The questionnaire was administered by a team of trained research assistants. 
2.5. Data Management. Field inspection of questionnaire data was carried out daily after the field interview was conducted, and any errors were immediately verified and corrected. The quantitative data generated was entered in Epidata 3.02 and then entered into Stata 12.0 (StataCorp, College Station, TX) statistical software for analysis.

\subsubsection{Definition of Variables}

(i) The occupational hazards were as follows. These hazards were broadly classified as biological and nonbiological. The broader classifications were generated as composite endpoints. Key questions asked included "Have you experienced any type of workrelated illness/injury/trauma (major and minor)? If yes: What was the cause?" Twenty structured responses included (1) slips, trips, and falls; (2) physical, psychological, sexual, and/or verbal abuse; (3) cuts/wounds/lacerations; (4) burns; (5) fracture; (6) sharp-related injuries (i.e., needles, etc.); (7) radon from X-rays and so forth; (8) chemical spill; (9) noise; (10) direct contact with contaminated specimens/biohazardous materials; (11) bioterrorism; (12) musculoskeletal injuries such as muscle aches/strains/sprains, carpel tunnel syndrome; (13) blood-borne path ogens; (14) infectious diseases/infections; (16) airborne diseases; (17) vector borne diseases; (18) stress; (19) crosscontamination from soiled materials; and (20) nonionizing radiation. These responses were sorted to generated the composite classifications, biological or nonbiological. Consequently,

(a) biological hazards were defined to include cuts/wounds/lacerations, sharp related injuries, direct contact with contaminated specimens/ biohazardous materials, bioterrorism, bloodborne pathogens, infectious diseases/infections, airborne diseases, vector borne diseases, and cross contamination from soiled materials;

(b) the nonbiological hazards were defined to include physical, psychosocial, and ergonomic hazards:

(1) the physical hazards included slips, trips, falls, burns, fracture, radiation from X-rays, noise, and nonionizing radiation;

(2) the psychosocial hazards included physical, psychosocial, sexual, and verbal abuse and stress;

(3) the ergonomic hazards were musculoskeletal injuries such as muscle aches/strains/ sprains and carpel tunnel syndrome.

2.6. Data Analysis. Data was analyzed using STATA 12 statistical software. To assess associations and independent predictors, we conducted binary and multivariate logistic regression modeling. The outcome variables used were experiencing either a biological or nonbiological hazard. Associations were
TABLE 2: Biological and nonbiological hazards experienced by health workers in major hospitals in Kampala, Uganda.

\begin{tabular}{lc}
\hline Hazards experienced by health workers & $\begin{array}{c}\text { Frequency } \\
(N=200) \\
\text { Yes (\%) }\end{array}$ \\
\hline $\begin{array}{l}\text { Biological hazards } \\
\text { Sharp related injuries (such as needle sticks) }\end{array}$ & $43(21.5)$ \\
Cuts and wounds & $34(17)$ \\
$\begin{array}{l}\text { Direct contact with contaminated } \\
\text { specimens/biohazardous materials }\end{array}$ & $21(10.5)$ \\
$\begin{array}{l}\text { Airborne diseases } \\
\text { Infectious diseases and/or infections }\end{array}$ & $18(9.0)$ \\
$\begin{array}{l}\text { Others (blood borne pathogens, vector borne } \\
\text { diseases, and bioterrorism) }\end{array}$ & $15(7.5)$ \\
Nonbiological hazards & $15(7.5)$ \\
$\begin{array}{l}\text { Stress } \\
\text { Physical, psychological, sexual, and/or verbal } \\
\text { abuse }\end{array}$ & $\mathbf{6 3 ( 3 1 . 5 )}$ \\
$\begin{array}{l}\text { Musculoskeletal injuries } \\
\text { Slips, trips, and/or falls }\end{array}$ & $43(21.5)$ \\
$\begin{array}{l}\text { Fractures } \\
\text { Others (chemical spills, noise, burns, and } \\
\text { radiations) }\end{array}$ & $21(10.5)$ \\
\hline
\end{tabular}

run between the respondent characteristics and the outcome variables to obtain the significant associations. A $P$ value of less than 0.05 was considered for a factor to be associated with experiencing the hazard.

2.7. Ethical Considerations. Ethical approval to carry out the study was obtained from Makerere University School of Public Health, Higher Degrees, Research and Ethics Committee, and the Uganda National Council of Science and Technology. Permission to conduct the study was obtained from the hospitals administration and each participant provided written informed consent.

\section{Results}

3.1. Biological and Nonbiological Hazards. Overall, half of the respondents reported experiencing an occupational health hazard. Among these, 39.5\% experienced biological hazards while $31.5 \%$ reported experiencing nonbiological hazards. Table 2 shows that the biological hazards mainly experienced by healthcare workers were sharp related injuries $(21.5 \%)$, cuts and wounds (17.0\%). The proportions of biological hazards (Table 3) were higher among healthcare workers who earned more than Ugx 500,000 per month $(<500,000(33.7 \%)$ versus $>500,00(44.8 \%))$, worked in government hospitals (government $(45.1 \%)$ versus others $(32.3 \%)$ ), never wore all necessary PPEs (wore all PPEs (30.4\%) versus others $(51.8 \%)$ ), worked over time (yes (45.4\%) versus no $(25.4 \%)$ ), worked in multiple health facilities (worked in multiple facilities (48.2\%) versus single facilities (36.1\%)), and experienced job 
TABLE 3: Occupational health and safety hazards experienced by health workers in major hospitals in Kampala, Uganda.

\begin{tabular}{|c|c|c|c|}
\hline Characteristic & Category & $\begin{array}{c}\text { Biological } \\
\text { hazard } \\
\text { Yes }(\%)\end{array}$ & $\begin{array}{c}\text { Nonbiological } \\
\text { hazard } \\
\text { Yes }(\%)\end{array}$ \\
\hline Overall & Total & $79(39.5)$ & $63(31.5)$ \\
\hline \multirow{2}{*}{ Sex } & Male & $23(40.3)$ & $15(26.3)$ \\
\hline & Female & $56(39.2)$ & $48(33.6)$ \\
\hline \multirow{2}{*}{ Age } & $\leq 30$ years & $35(38.9)$ & $21(23.3)$ \\
\hline & $>30$ years & $44(40.0)$ & $42(38.2)$ \\
\hline \multirow{2}{*}{$\begin{array}{l}\text { Cadre of health } \\
\text { worker }\end{array}$} & Nurses & $40(39.6)$ & $37(36.6)$ \\
\hline & Others & $39(39.4)$ & $26(26.3)$ \\
\hline \multirow{2}{*}{ Monthly income } & $\leq 500,000$ & $32(33.7)$ & $24(25.3)$ \\
\hline & $>500,000$ & $47(44.8)$ & $39(37.1)$ \\
\hline \multirow{3}{*}{$\begin{array}{l}\text { Type of health care } \\
\text { facility }\end{array}$} & Faith based & $13(27.1)$ & $13(27.1)$ \\
\hline & Private & $29(41.4)$ & $18(25.7)$ \\
\hline & Government & $37(45.1)$ & $32(39.0)$ \\
\hline \multirow{2}{*}{ Duration in service } & $<5$ years & $36(38.3)$ & $23(24.5)$ \\
\hline & $\geq 5$ years & $43(40.6)$ & $40(37.7)$ \\
\hline \multirow{2}{*}{$\begin{array}{l}\text { Wearing all } \\
\text { necessary PPE }\end{array}$} & Yes & $35(30.4)$ & $25(21.7)$ \\
\hline & No & $44(51.8)$ & $38(44.7)$ \\
\hline \multirow{2}{*}{ Working overtime } & No & $15(25.4)$ & $11(18.6)$ \\
\hline & Yes & $64(45.4)$ & $52(36.9)$ \\
\hline \multirow{2}{*}{$\begin{array}{l}\text { Working in } \\
\text { multiple facilities }\end{array}$} & No & $52(36.1)$ & $40(27.8)$ \\
\hline & Yes & $27(48.2)$ & $23(41.1)$ \\
\hline \multirow{2}{*}{$\begin{array}{l}\text { Daily hours of } \\
\text { sleep }\end{array}$} & $<8$ hours & $64(42.7)$ & $51(34.0)$ \\
\hline & $\geq 8$ hours & $15(30.0)$ & $12(24.0)$ \\
\hline \multirow{2}{*}{ Pressure from job } & No & $3(9.1)$ & $2(6.1)$ \\
\hline & Yes & $76(45.5)$ & $61(36.5)$ \\
\hline
\end{tabular}

related pressure (experienced job pressure $(45.5 \%)$ versus others (9.1\%)).

Among those that experienced nonbiological hazards (Table 2), the majority experienced stress (21.5\%), physical, psychological, sexual, and/or verbal abuse (10.5\%), and musculoskeletal injuries (10.5\%). The proportions of nonbiological hazards (Table 3 ) were higher among females (male $(26.3 \%)$ versus female $(33.6 \%)$ ), those older than 30 years $(\leq 30$ years $(23.3 \%)$ versus $>30$ years $(38.2 \%))$, those who earned higher monthly incomes $(\leq 500,000(25.3 \%)$ versus $>500,000(37.1 \%))$, those who worked in governmental facilities (government (39.0\%) versus others $(23.8 \%)$ ), those with more than five-year duration in service $(\leq 5$ years $(24.5 \%)$ versus $>5$ years $(37.7 \%))$, those who never wore all the necessary PPEs (wore all necessary PPEs $(21.7 \%$ ) versus others $(44.7 \%)$ ), worked over time (yes (36.9\%) versus no $(18.6 \%))$, those who worked in multiple health facilities (multiple $(41.1 \%)$ versus others $(27.8 \%)$ ), those who had less than 8 hours of daily sleep ( $<8$ hours $(34.0 \%)$ versus others $(24.0 \%))$, and those who experienced work related pressure (experienced pressure (36.5\%) versus others (6.1\%)).

3.2. Factors Associated with Exposure to Biological and Nonbiological Hazards. Table 4 shows the crude odds ratios for the associations between the respondents' characteristics and work related exposures. Biological hazards were associated with working in a government facility [COR $=2.21(1.02-$ 4.78), $P=0.043$ ], not wearing all the necessary personal protective equipment [COR $=2.45(1.37-4.39), P=0.003$ ], working overtime $[\mathrm{COR}=2.44(1.24-4.78), P=0.009]$, and experiencing work related pressure [COR $=8.35(2.45-$ 28.4), $P=0.001$ ]. Nonbiological hazards were associated with working in medical field for more than 5 years [COR = 1.87 (1.01-3.45), $P=0.045$ ], working overtime [COR $=2.55$ (1.22-5.34), $P=0.013$ ], not wearing all necessary personal protective equipment $[\mathrm{AOR}=2.45$ (1.57-5.39), $P=0.006$ ], and experiencing job related pressure $[\mathrm{COR}=8.92(2.06-$ 38.57), $P=0.003$.

At multivariate analysis (Table 5), the independent predictors for experiencing a biological hazard were not wearing necessary personal protective equipment $[\mathrm{AOR}=2.34$ (1.294.64), $P=0.006$ ], working overtime $[\mathrm{AOR}=2.65$ (1.31-5.37), $P=0.007$, and experiencing job related pressures $[\mathrm{AOR}=$ 8.54 (1.11-4.61), $P=0.001]$. Meanwhile, the independent predictors for experiencing nonbiological hazards were not wearing all necessary personal protective equipment $[\mathrm{AOR}=$ 2.45 (1.29-4.64), $P=0.006$ ], working overtime [AOR $=2.38$ (1.10-5.14), $P=0.028$ ], working in multiple health facilities 
TABLE 4: Crude odds ratios (COR) for the predictors of experiencing biological and nonbiological hazards among health workers in major hospitals in Kampala, Uganda.

\begin{tabular}{|c|c|c|c|c|c|}
\hline \multirow{2}{*}{ Characteristic } & \multirow{2}{*}{ Category } & \multicolumn{2}{|c|}{ Biological hazards } & \multicolumn{2}{|c|}{ Nonbiological hazards } \\
\hline & & COR $[95 \% \mathrm{CI}]$ & $P$ value & COR $[95 \% \mathrm{CI}]$ & $P$ value \\
\hline Overall & Total & $N=79$ & & $N=63$ & \\
\hline \multirow{2}{*}{ Sex } & Male & 1 & & 1 & \\
\hline & Female & $0.95[0.51-1.78]$ & 0.877 & $1.41[0.71-2.80]$ & 0.32 \\
\hline \multirow{2}{*}{ Age } & $\leq 30$ years & 1 & & 1 & \\
\hline & $>30$ years & $1.04[0.59-1.85]$ & 0.873 & $2.03[1.09-3.78]$ & $0.026^{*}$ \\
\hline \multirow{2}{*}{ Cadre of health worker } & Nurses & 1 & & 1 & \\
\hline & Others & $0.99[0.56-1.75]$ & 0.976 & $0.62[0.34-1.13]$ & 0.116 \\
\hline \multirow{2}{*}{ Monthly income } & $\leq 500,000$ & 1 & & 1 & \\
\hline & $>500,000$ & $1.59[0.89-2.83]$ & 0.11 & $1.75[0.95-3.21]$ & 0.072 \\
\hline \multirow{3}{*}{ Type of health care facility } & Faith based & 1 & & 1 & \\
\hline & Private & $1.90[0.86-4.21]$ & 0.112 & $0.93[0.40-2.14]$ & 0.868 \\
\hline & Government & $2.21[1.02-4.78]$ & $0.043^{*}$ & $1.72[0.79-3.74]$ & 0.169 \\
\hline \multirow{2}{*}{ Duration in service } & $<5$ years & 1 & & 1 & \\
\hline & $\geq 5$ years & $1.09[0.62-1.94]$ & 0.743 & $1.87[1.01-3.45]$ & $0.045^{*}$ \\
\hline \multirow{2}{*}{ Wearing all necessary PPE } & Yes & 1 & & 1 & \\
\hline & No & $2.45[1.37-4.39]$ & $0.003^{* *}$ & $2.91[1.57-5.39]$ & $0.001^{* *}$ \\
\hline \multirow{2}{*}{ Working overtime } & No & 1 & & 1 & \\
\hline & Yes & $2.44[1.24-4.78]$ & $0.009^{* *}$ & $2.55[1.22-5.34]$ & $0.013^{*}$ \\
\hline \multirow{2}{*}{ Working in multiple facilities } & No & 1 & & 1 & \\
\hline & Yes & $1.65[0.88-3.08]$ & 0.117 & $1.81[0.95-3.45]$ & 0.071 \\
\hline \multirow{2}{*}{ Daily hours of sleep } & $<8$ hours & 1 & & 1 & \\
\hline & $\geq 8$ hours & $0.57[0.29-1.14]$ & 0.115 & $0.61[0.29-1.27]$ & 0.19 \\
\hline \multirow{2}{*}{ Pressure from job } & No & 1 & & 1 & \\
\hline & Yes & $8.35[2.45-28.4]$ & $0.001^{* *}$ & $8.92[2.06-38.57]$ & $\mathbf{0 . 0 0 3}^{* *}$ \\
\hline
\end{tabular}

${ }^{*} P<0.05 ;{ }^{* *} P<0.01$ indicates association between variables.

[AOR $=2.26(1.11-4.61), P=0.024]$, and experiencing job related pressures $[\mathrm{AOR}=9.69(2.19-42.9), P=0.003]$ (Table 5).

3.3. Control Measures for Occupational Health Hazards. We made an inquiry into the occupational measures in place to control occupational health hazards. Table 6 shows the health facility and individual measures that were in place to control occupational health hazards. The major control measures provided by the health facilities were availing separate areas and containers to dispose medical waste $(92.0 \%)$ and safety tools and equipment (90.0\%). More than half (53.5\%) of the health facilities provided health workers with personal protective equipment. Almost all healthcare workers had received HIV screening examination $(97.0 \%)$ and $91.0 \%$ had received BCG vaccination. Regarding the hand washing practices, most health workers washed their hands before and after every procedure $(79.5 \%)$ and after handling soiled materials (68.5\%). Forty six percent of health workers washed hands when they were evidently dirty while slightly over half $(53.5 \%)$ did so after using the toilet.

\section{Discussion}

This study highlights that half of respondents had experienced an occupational health hazard, mostly sharp related injuries and stress. The likely predictors for both biological and nonbiological hazards were not wearing all the necessary personal protective equipment, were working overtime, and were job related pressures. In addition, nonbiological hazards were predicted by working in multiple health facilities. The mitigation measures to control the hazards were mainly availing waste disposal facilities for the medical waste and provision of safety tools and equipment.

These findings are largely comparable to previous studies conducted in low and middle income countries. Ziraba in Uganda, Nsubuga in Uganda, Orij in Nigeria, De Castro in Philippines, and Adib-Hajbaghery in Iran reported that sharp related injuries and stress were the major health related hazards experienced by healthcare workers in their studies $[6,18-21]$.

In our study, we established that using all the necessary personal protective equipment was associated with reduced exposure to both biological and nonbiological hazards. This finding supports evidence by Hayden et al., who reported that use of PPEs reduced acquisition of illnesses in hospital settings [22]. Indeed, use and compliance with utilization of PPEs has for long been recognized as important infection control measure in the healthcare industry $[23,24]$ which should be emphasized to minimize exposure to occupational hazards.

In addition, we found that respondents who worked overtime had increased likelihood of experiencing both biological and nonbiological hazards. This is consistent with previous 
TABLE 5: Adjusted odds ratios (AOR) for the predictors of experiencing biological and nonbiological hazards among health workers in major hospitals in Kampala, Uganda.

\begin{tabular}{|c|c|c|c|c|c|}
\hline \multirow{2}{*}{ Characteristic } & \multirow{2}{*}{ Category } & \multicolumn{2}{|c|}{ Biological hazards } & \multicolumn{2}{|c|}{ Nonbiological hazards } \\
\hline & & $\operatorname{AOR}[95 \% \mathrm{CI}]$ & $P$ value & $\operatorname{AOR}[95 \% \mathrm{CI}]$ & $P$ value \\
\hline Overall & Total & $N=79$ & & $N=63$ & \\
\hline \multirow{2}{*}{ Sex } & Male & 1 & & 1 & \\
\hline & Female & $1.09[0.54-2.22]$ & 0.796 & $1.32[0.61-2.87]$ & 0.488 \\
\hline \multirow{2}{*}{ Age } & $\leq 30$ years & 1 & & 1 & \\
\hline & $>30$ years & $1.23[0.62-2.41]$ & 0.553 & $2.02[0.97-4.19]$ & 0.059 \\
\hline \multirow{2}{*}{ Cadre of health worker } & Nurses & 1 & & 1 & \\
\hline & Others & $1.06[0.56-2.01]$ & 0.858 & $0.76[0.38-1.51]$ & 0.434 \\
\hline \multirow{2}{*}{ Monthly income } & $\leq 500,000$ & 1 & & 1 & \\
\hline & $>500,000$ & $1.52[0.82-2.81]$ & 0.180 & $1.74[0.90-3.37]$ & 0.097 \\
\hline \multirow{3}{*}{ Type of health care facility } & Faith based & 1 & & 1 & \\
\hline & Private & $1.88[0.79-4.43]$ & 0.151 & $0.93[0.37-2.30]$ & 0.872 \\
\hline & Government & $1.96[0.87-4.44]$ & 0.105 & $1.43[0.62-3.29]$ & 0.398 \\
\hline \multirow{2}{*}{ Duration in service } & $<5$ years & 1 & & 1 & \\
\hline & $\geq 5$ years & $1.21[0.49-2.98]$ & 0.68 & $1.22[0.58-2.82]$ & 0.686 \\
\hline \multirow{2}{*}{ Wearing all necessary PPE } & Yes & 1 & & 1 & \\
\hline & No & $2.34[1.27-4.28]$ & $0.006^{* *}$ & $2.45[1.29-4.64]$ & $0.006^{* *}$ \\
\hline \multirow{2}{*}{ Working overtime } & No & 1 & & 1 & \\
\hline & Yes & $2.65[1.31-5.37]$ & $0.007^{* *}$ & $2.38[1.10-5.14]$ & $0.028^{*}$ \\
\hline \multirow{2}{*}{ Working in multiple facilities } & No & 1 & & 1 & \\
\hline & Yes & $1.69[0.88-3.29]$ & 0.116 & $2.26[1.11-4.61]$ & $0.024^{*}$ \\
\hline \multirow{2}{*}{ Daily hours of sleep } & $<8$ hours & 1 & & 1 & \\
\hline & $\geq 8$ hours & $0.57[0.28-1.17]$ & 0.125 & $0.56[0.26-1.22]$ & 0.145 \\
\hline \multirow{2}{*}{ Pressure from job } & No & 1 & & 1 & \\
\hline & Yes & $8.54[2.48-29.4]$ & $0.001^{* *}$ & $9.69[2.19-42.9]$ & $0.003^{* *}$ \\
\hline
\end{tabular}

${ }^{*} P<0.05 ;{ }^{* *} P<0.01$ indicates association between variables.

literature that reported increased risk of experiencing occupational hazards [21, 25-31]. Long working hours results in prolonged exposures to hazards and limited recovery time $[32,33]$ which translates into physiologic depletion that continues to the next workday [34]. Other studies have shown that working long hours is also associated with adverse health effects $[31,35,36]$ and unhealthy behaviors [37]. This mode of work has also raised concern about patient safety [38]. We also found that respondents who experienced work related pressures were more likely to report occupational hazards. Work related pressures have been reported to have negative impacts including the compromise of patient care thus resulting to a diminished quality of life for both healthcare workers and patients $[39,40]$. Another interesting finding although not significant at multivariate analysis was the association between working in a government health facility and experiencing occupational hazards compared to private health facilities. Reasons for this discrepancy may need to be explored further.

Although many health facilities provided waste disposal facilities for the medical waste and safety tools and equipment as control measures for occupational health hazards, simple measures like hand washing were not fully embraced. The proportion of health workers who reported washing hands after recommended procedures was lower than has been reported by previous studies [41, 42]. On the other hand, it was encouraging to establish that the majority of health workers had been screened for HIV and 8 in 10 health workers had been vaccinated against hepatitis $B$.

4.1. Study Limitations. This study was carried out in the major hospitals which limit generalizability to small and rural health facilities. The results could have been affected by recall bias as respondents were required to recall past experience. This being a cross sectional study, cause effect could not be established. Nevertheless, this study provides useful information on occupational health hazards in this low income context.

\section{Conclusion}

Healthcare workers continue to face several hazards in their workplaces. The factors associated with experiencing hazards include not wearing all necessary protective equipment, working overtime, experiencing work related pressures, and working in multiple facilities. Interventions should be instituted to mitigate the hazards. Specifically PPE supply gaps, 
TABLE 6: Control measures to minimize exposure to occupational health and safety hazards among health workers in Kampala, Uganda.

\begin{tabular}{|c|c|}
\hline \multirow[t]{2}{*}{ Occupational health control measures } & $\begin{array}{l}\text { Frequency } \\
(N=200)\end{array}$ \\
\hline & $N(\%)$ \\
\hline \multicolumn{2}{|l|}{ Control measures provided by employers } \\
\hline $\begin{array}{l}\text { Safety education \& training on all universal } \\
\text { precautions }\end{array}$ & $126(63.0)$ \\
\hline Safety tools, equipment, and machinery & $180(90.0)$ \\
\hline Training on all machinery and equipment used & $114(57.0)$ \\
\hline Training on how to wash hands & $177(88.5)$ \\
\hline Personal set of personal protective equipment & $107(53.5)$ \\
\hline $\begin{array}{l}\text { Separate areas and containers to dispose } \\
\text { medical waste }\end{array}$ & $184(92.0)$ \\
\hline \multicolumn{2}{|l|}{ Individual protective measures } \\
\hline BCG vaccination & $183(91.5)$ \\
\hline Hepatitis A vaccination & $64(32.0)$ \\
\hline Hepatitis B vaccination & $156(78.0)$ \\
\hline Provision of postexposure prophylaxis & $164(82.0)$ \\
\hline Ever received postexposure prophylaxis* & $43(21.5)$ \\
\hline Received HIV screening examination & $194(97.0)$ \\
\hline \multicolumn{2}{|l|}{ Hand washing practices } \\
\hline After handling soiled materials & $137(68.5)$ \\
\hline When hands are evidently dirty & $92(46.0)$ \\
\hline Before and after meals & $124(62.0)$ \\
\hline After using the toilet & $107(53.5)$ \\
\hline After removing gloves & $133(66.5)$ \\
\hline Before and after every procedure & $159(79.5)$ \\
\hline Before and after handling each patient & $136(68.0)$ \\
\hline After handling biological samples & $136(68.0)$ \\
\hline Before and after handling hazardous materials & $106(53.0)$ \\
\hline
\end{tabular}

* Only received in case of exposure to HIV.

job related pressures, and complacence in adhering to mitigation measures should be addressed.

\section{Disclaimer}

The funders had no role in the design, implementation and writing of the paper and decision to publish this paper.

\section{Conflict of Interests}

All authors declare no conflict of interests.

\section{Acknowledgment}

This study was funded by the National Institute of Health (Grant nos. 1R24TW009489 and 1R24TW009556).

\section{References}

[1] M. Goniewicz, A. Włoszczak-Szubzda, M. Niemcewicz, M. Witt, A. Marciniak-Niemcewicz, and M. J. Jarosz, "Injuries caused by sharp instruments among healthcare workersinternational and Polish perspectives," Annals of Agricultural and Environmental Medicine, vol. 19, no. 3, pp. 523-527, 2012.

[2] R. M. Moore Jr. and R. G. Kaczmarek, “Occupational hazards to health care workers: diverse, ill-defined, and not fully appreciated," American Journal of Infection Control, vol. 18, no. 5, pp. 316-327, 1990.

[3] J. Salvage, R. Rogers, and R. Cowell, "Nurses at risk," Nursing times, vol. 94, no. 33, pp. 34-35, 1998.

[4] P. K. Triolo, "Occupational health hazards of hospital staff nurses. Part II: physical, chemical, and biological stressors," AAOHN Journal, vol. 37, no. 7, pp. 274-279, 1989.

[5] S. V. Manyele, H. A. Ngonyani, and E. Eliakimu, "The status of occupational safety among health service providers in hospitals in Tanzania," Tanzania Journal of Health Research, vol. 10, no. 3, pp. 159-165, 2008.

[6] F. M. Nsubuga and M. S. Jaakkola, "Needle stick injuries among nurses in sub-Saharan Africa," Tropical Medicine and International Health, vol. 10, no. 8, pp. 773-781, 2005.

[7] J. Lipscomb and L. Rosenstock, "Healthcare workers: protecting those who protect our health," Infection Control and Hospital Epidemiology, vol. 18, no. 6, pp. 397-399, 1997. 
[8] L. L. Andersen, T. Clausen, O. S. Mortensen, H. Burr, and A. Holtermann, "A prospective cohort study on musculoskeletal risk factors for long-term sickness absence among healthcare workers in eldercare," International Archives of Occupational and Environmental Health, vol. 85, no. 6, pp. 615-622, 2012.

[9] W. Ijzelenberg and A. Burdorf, "Risk factors for musculoskeletal symptoms and ensuing health care use and sick leave," Spine, vol. 30, no. 13, pp. 1550-1556, 2005.

[10] S. Q. Wilburn and G. Eijkemans, "Preventing needlestick injuries among healthcare workers: a WHO-ICN collaboration," International Journal of Occupational and Environmental Health, vol. 10, no. 4, pp. 451-456, 2004.

[11] J. A. Johansson, "Psychosocial work factors, physical work load and associated musculoskeletal symptoms among home care workers." Scandinavian Journal of Psychology, vol. 36, no. 2, pp. 113-129, 1995.

[12] HSE, Moving and handling in health and social care, Health and safety executive.

[13] WHO, The World Health Report Working Together for Health, World Health Organization, Geneva, Switzerland, 2006.

[14] D. Y. Dovlo, "Using mid-level cadres as substitutes for internationally mobile health professionals in Africa. A desk review," Human Resources for Health, vol. 2, no. 1, article 7, 2004.

[15] D. Dovlo, "Taking more than a fair share? The migration of health professionals from poor to rich countries," PLoS Medicine, vol. 2, no. 5, article e109, 2005.

[16] B. M. Tinubu, C. E. Mbada, A. L. Oyeyemi, and A. A. Fabunmi, "Work-related musculoskeletal disorders among nurses in Ibadan, South-west Nigeria: a cross-sectional survey," BMC Musculoskeletal Disorders, vol. 11, article 12, 2010.

[17] Uganda Bureau of Statistics (UBOS), Statistical Abstract, 2010.

[18] A. K. Ziraba, J. Bwogi, A. Namale, C. W. Wainaina, and H. Mayanja-Kizza, "Sero-prevalence and risk factors for hepatitis B virus infection among health care workers in a tertiary hospital in Uganda," BMC Infectious Diseases, vol. 10, article 191, 2010.

[19] E. O. Orji, O. B. Fasubaa, U. Onwudiegwu, F. O. Dare, and S. O. Ogunniyi, "Occupational health hazards among health care workers in an obstetrics and gynaecology unit of a Nigerian teaching hospital," Journal of Obstetrics \& Gynaecology, vol. 22, no. 1, pp. 75-78, 2002.

[20] M. Adib-Hajbaghery and M. S. Lotfi, "Behavior of healthcare workers after injuries from sharp instruments," Trauma Monthly, vol. 18, no. 2, pp. 75-80, 2013.

[21] A. B. de Castro, S. L. Cabrera, G. C. Gee, K. Fujishiro, and E. A. Tagalog, "Occupational health and safety issues among nurses in the Philippines," AAOHN Journal, vol. 57, no. 4, pp. 149-157, 2009.

[22] M. K. Hayden, D. W. Blom, E. A. Lyle, C. G. Moore, and R. A. Weinstein, "Risk of hand or glove contamination after contact with patients colonized with vancomycin-resistant Enterococcus or the colonized patients' environment," Infection Control and Hospital Epidemiology, vol. 29, no. 2, pp. 149-154, 2008.

[23] E. A. Bolyard, O. C. Tablan, W. W. Williams, M. L. Pearson, C. N. Shapiro, and S. D. Deitchmann, "Guideline for infection control in healthcare personnel, 1998. Hospital infection control practices advisory committee," Infection Control and Hospital Epidemiology, vol. 19, no. 6, pp. 407-463, 1998.

[24] J. D. Siegel, E. Rhinehart, M. Jackson, and L. Chiarello, “2007 guideline for isolation precautions: preventing transmission of infectious agents in health care settings," American Journal of Infection Control, vol. 35, supplement 2, no. 10, pp. S65-S164, 2007.
[25] J. A. Lipscomb, A. M. Trinkoff, J. Geiger-Brown, and B. Brady, "Work-schedule characteristics and reported musculoskeletal disorders of registered nurses," Scandinavian Journal of Work, Environment and Health, vol. 28, no. 6, pp. 394-401, 2002.

[26] B. D. Kirkcaldy, R. Trimpop, and C. L. Cooper, "Working hours, job stress, work satisfaction, and accident rates among medical practitioners and allied personnel," International Journal of Stress Management, vol. 4, no. 2, pp. 79-87, 1997.

[27] A. Trinkoff, J. Geiger-Brown, B. Brady, J. Lipscomb, and C. Muntaner, "How long and how much are nurses now working?" The American Journal of Nursing, vol. 106, no. 4, pp. 60-72, 2006.

[28] M. N. Ilhan, E. Durukan, E. Aras, S. Türkçüoǧlu, and R. Aygün, "Long working hours increase the risk of sharp and needlestick injury in nurses: the need for new policy implication," Journal of Advanced Nursing, vol. 56, no. 5, pp. 563-568, 2006.

[29] R. R. M. Gershon, J. M. Pearson, M. F. Sherman, S. M. Samar, A. N. Canton, and P. W. Stone, "The prevalence and risk factors for percutaneous injuries in registered nurses in the home health care sector," The American Journal of Infection Control, vol. 37, no. 7, pp. 525-533, 2009.

[30] S. W. Lockley, L. K. Barger, N. T. Ayas, J. M. Rothschild, C. A. Czeisler, and C. P. Landrigan, "Effects of health care provider work hours and sleep deprivation on safety and performance," Joint Commission Journal on Quality and Patient Safety, vol. 33, no. 11, supplement, pp. 7-18, 2007.

[31] A. E. Dembe, J. B. Erickson, R. G. Delbos, and S. M. Banks, "The impact of overtime and long work hours on occupational injuries and illnesses: new evidence from the United States," Occupational and Environmental Medicine, vol. 62, no. 9, pp. 588-597, 2005.

[32] F. N. da Silva Borges and F. M. Fischer, "Twelve-hour night shifts of healthcare workers: a risk to the patients?" Chronobiology International, vol. 20, no. 2, pp. 351-360, 2003.

[33] C. C. Caruso, T. Bushnell, D. Eggerth et al., "Long working hours, safety, and health: toward a national research agenda," American Journal of Industrial Medicine, vol. 49, no. 11, pp. 930942, 2006.

[34] R. R. Rosa, "Extended workshifts and excessive fatigue," Journal of Sleep Research, vol. 4, supplement s2, pp. 51-56, 1995.

[35] G. Costa, S. Sartori, and T. Åkerstedt, "Influence of flexibility and variability of working hours on health and well-being," Chronobiology International, vol. 23, no. 6, pp. 1125-1137, 2006.

[36] S. Vegso, L. Cantley, M. Slade et al., "Extended work hours and risk of acute occupational injury: a case-crossover study of workers in manufacturing," American Journal of Industrial Medicine, vol. 50, no. 8, pp. 597-603, 2007.

[37] M. van der Hulst, "Long workhours and health," Scandinavian Journal of Work, Environment and Health, vol. 29, no. 3, pp. 171$188,2003$.

[38] A. E. Rogers, W.-T. Hwang, L. D. Scott, L. H. Aiken, and D. F. Dinges, "The working hours of hospital staff nurses and patient safety," Health Affairs, vol. 23, no. 4, pp. 202-212, 2004.

[39] P. M. Conway, P. Campanini, S. Sartori, R. Dotti, and G. Costa, "Main and interactive effects of shiftwork, age and work stress on health in an Italian sample of healthcare workers," Applied Ergonomics, vol. 39, no. 5, pp. 630-639, 2008.

[40] A. Berland, G. K. Natvig, and D. Gundersen, "Patient safety and job-related stress: a focus group study," Intensive and Critical Care Nursing, vol. 24, no. 2, pp. 90-97, 2008.

[41] A. Kotwal, V. Anargh, H. Singh, A. Kulkarni, and A. Mahen, "Hand hygiene practices among health care workers (HCWs) 
in a tertiary care facility in Pune," Medical Journal Armed Forces India, vol. 69, no. 1, pp. 54-56, 2013.

[42] S. Joshi, A. Joshi, B. J. Park, and U. R. Aryal, "Hand washing practice among health care workers in a teaching hospital," Journal of Nepal Health Research Council, vol. 11, no. 23, pp. 1-5, 2013. 


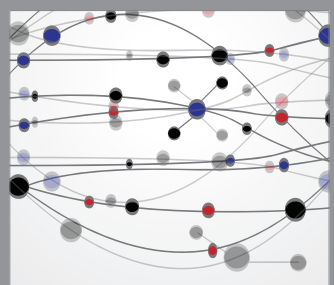

The Scientific World Journal
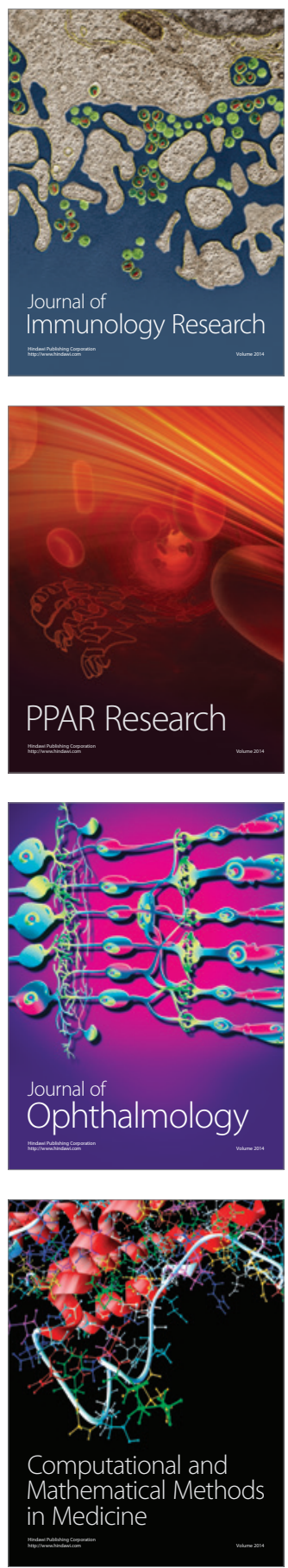

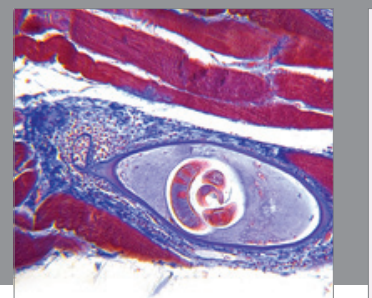

Gastroenterology

Research and Practice
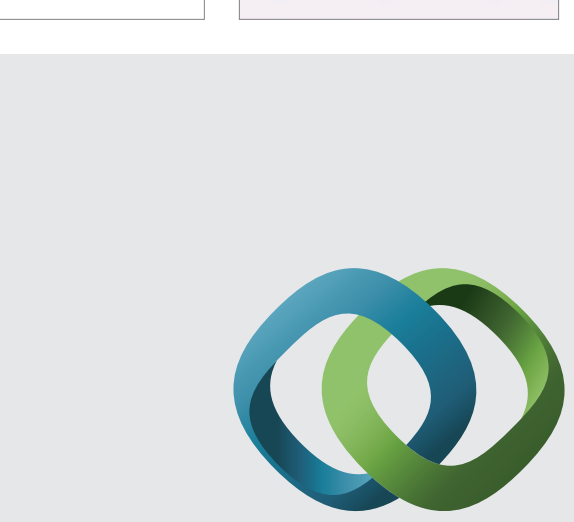

\section{Hindawi}

Submit your manuscripts at

http://www.hindawi.com
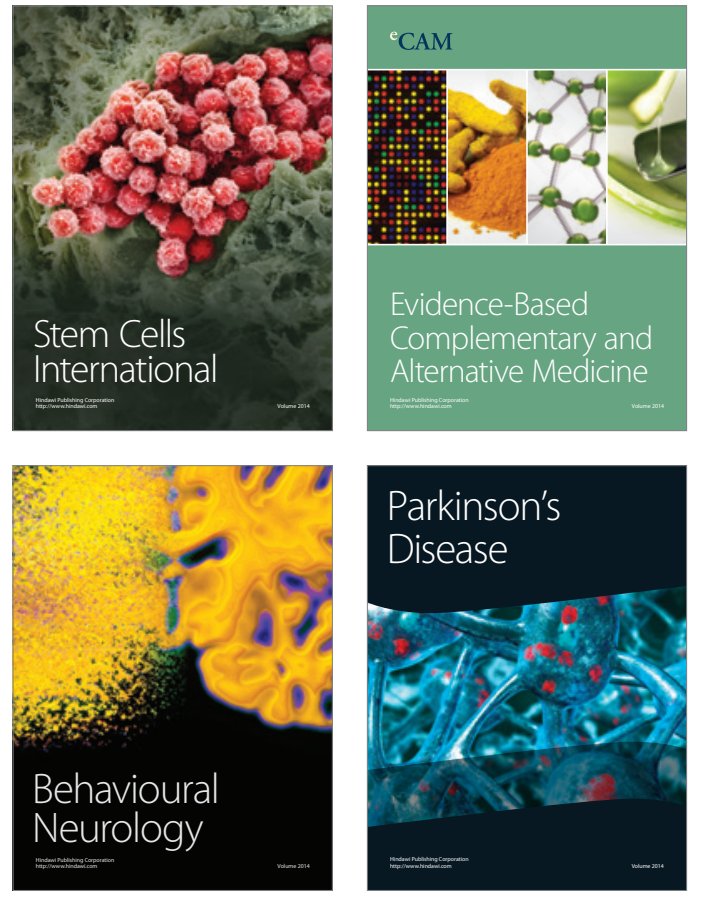
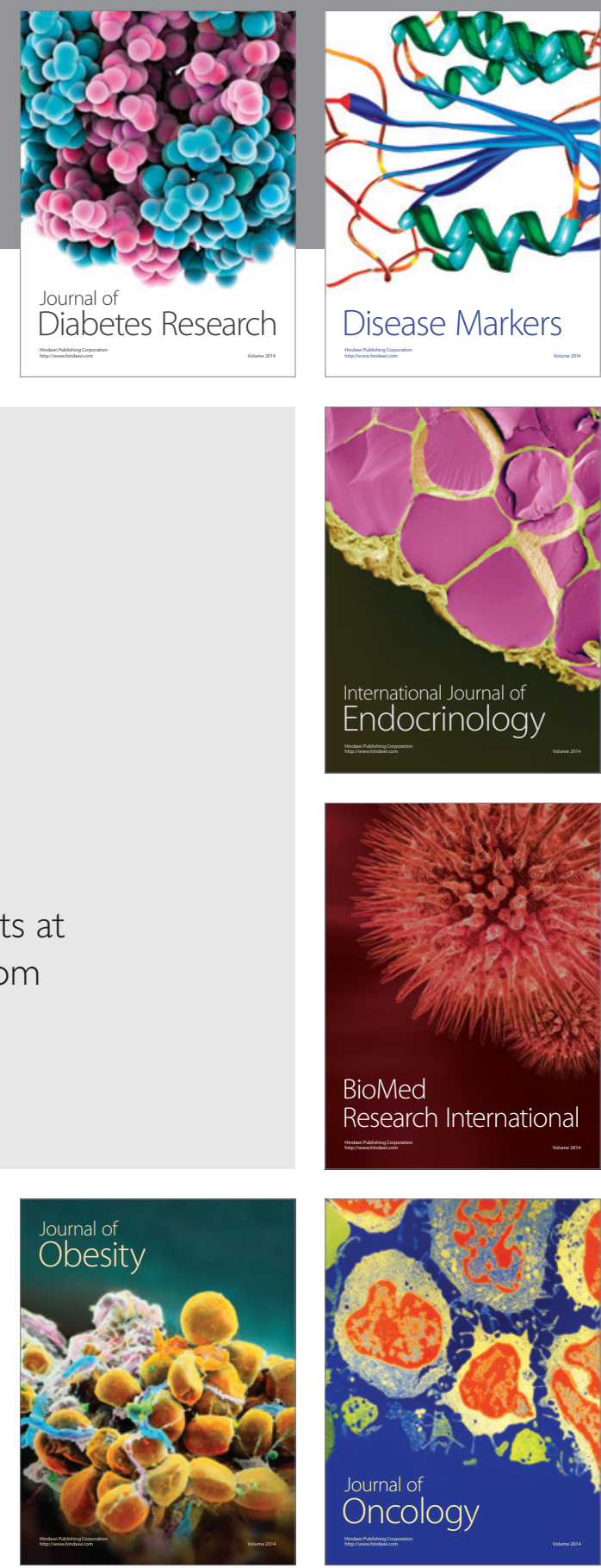

Disease Markers
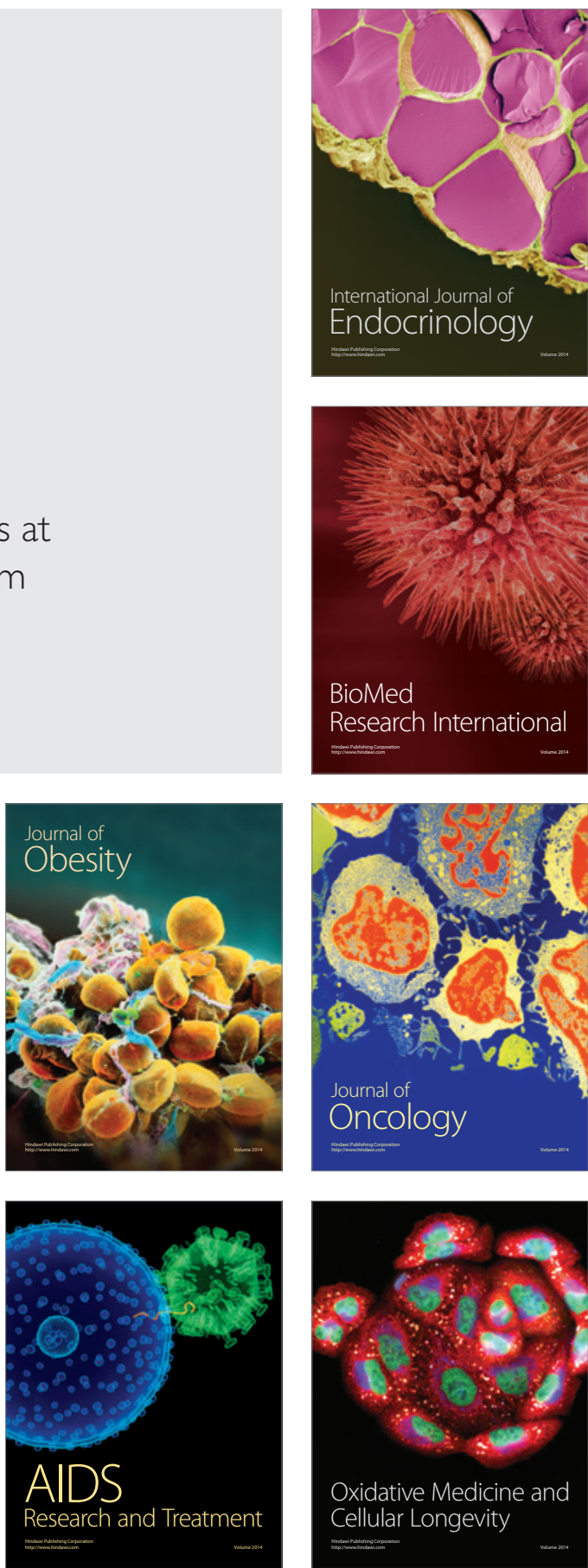